University of Nebraska - Lincoln

DigitalCommons@University of Nebraska - Lincoln

June 1994

\title{
Differential resource consumption obviates a potential flight-fecundity trade-off in the sand cricket (Gryllus firmus)
}

\author{
S. Mole \\ University of Nebraska - Lincoln
}

Anthony J. Zera

University of Nebraska - Lincoln, azera1@unl.edu

Part of the Microbiology Commons

Mole, S. and Zera, Anthony J., "Differential resource consumption obviates a potential flight-fecundity trade-off in the sand cricket (Gryllus firmus)" (1994). Anthony Zera Publications. 19.

https://digitalcommons.unl.edu/bioscizera/19

This Article is brought to you for free and open access by the Papers in the Biological Sciences at DigitalCommons@University of Nebraska - Lincoln. It has been accepted for inclusion in Anthony Zera Publications by an authorized administrator of DigitalCommons@University of Nebraska - Lincoln. 


\title{
Differential resource consumption obviates a potential flight- fecundity trade-off in the sand cricket (Gryllus firmus)
}

\author{
S. Mole and A. J. Zera \\ School of Biological Sciences, 348 Manter Hall, \\ University of Nebraska-Lincoln, Lincoln, NE 68588-0118, USA
}

\begin{abstract}
Summary
1. The physiological basis of life-history trade-offs is poorly understood. A useful system in which the underlying physiological mechanisms can be studied is wing polymorphism in insects.

2. The sand cricket, Gryllus firmus (Orthoptera, Gryllidae), exists in natural populations as either a fullywinged (LW), flight-capable morph or as a short-winged (SW) morph that cannot fly.

3. We characterized the morphs with respect to physiological features that influence a potential trade-off between flight capability and fecundity. We measured nutritional indices, flight muscle development and ovarian development in the LW and SW morphs.

4. In adults, ovarian growth occurred after the completion of flight muscle growth which precludes a direct trade-off of resources devoted to the growth of these two organs.

5. In feeding trials with adult female crickets, the efficiency with which assimilated nutrients were converted to new tissue growth was significantly lower in LW vs SW morphs. This result is consistent with the existence of a metabolic cost resulting from the maintenance of the large flight muscles in the LW morph, which are not present in the SW morph.

6. Despite this reduced efficiency, total biomass gain, ovarian growth and the number of eggs oviposited did not differ between morphs. This was the result of increased food acquisition by LW vs SW females in these trials, in which crickets were fed a nutritious diet ad libitum.

7. The LW morph of G. firmus can counter the energetic demands of flight capability by consuming additional food and thus can avoid a cost in terms of reduced fecundity and so obviate the trade-off.

8. Trade-offs may be generally obviated when neither environmental supply nor the organismal processes of digestion and absorption limit resource availability.

Keywords: Dispersal, flight-oogenesic syndrome, Gryllidae, life history, Orthoptera, resource acquisition, resource allocation, wing polymorphism
\end{abstract}

\section{Introduction}

An important but unresolved issue in life-history evolution is the nature of the associations among life-history traits. Many cases of negative trait associations have been documented, such as reduced reproductive effort and increased survivorship (Roff 1992; Stearns 1992). Such associations, where an increase in one trait is correlated with a decrease in another, are generally referred to as tradeoffs (Reznick 1983; Begon, Harper \& Townsend 1986;
Stearns 1989). Such negative associations are not universal. Sometimes they fail to occur (Nylin et al. 1993) and occasionally, unexpected positive associations are found (Tuomi, Haukioja \& Hakala 1983; Haukioja \& Hakala 1986). A major issue awaiting resolution concerns the mechanisms underlying both the positive and negative interactions between life-history traits (Stearns 1992; Mole \& Zera 1993).

It is often thought that life-history trade-offs seen at the phenotypic level are underpinned by trade-offs of resources 
at the physiological level. That is, macro- or microevolutionary changes resulting in an increased allocation to one trait require a concomitant decreased allocation to another or others (Fisher 1930; Williams 1966; Calow 1979; Pianka 1981; Reekie \& Bazzaz 1987). An assumption which underlies this argument is that resources are limited within the organism. Despite widespread acceptance of this notion of trade-offs in the literature, little is known about the physiological basis for such trade-offs or for the underlying assumption of resource limitation.

A useful system in which the physiological mechanisms underlying trade-offs can be studied is wing polymorphism in insects. The polymorphism is thought to represent an extreme case of the antagonism between lifehistory traits associated with flight and reproduction (flightoogenesis syndrome; Johnson 1969). At one extreme there is a long-winged phenotype which is less fecund but capable of flight. At the other extreme, there is a highly fecund short-winged phenotype, in which the flight apparatus (wings, flight muscle, flight fuels) does not fully develop. The negative association between flight and reproductive capabilities, in this common insect polymorphism (Harrison 1980; Penes 1985; Roff 1986), is thought to result from a parallel trade-off of internal resources. In the flightless morph, resources that would have been allocated to the flight apparatus are allocated to egg production. It is only recently that this trade-off has been documented at the internal resource level (Mole \& Zera 1993; Tanaka 1993).

In the wing-polymorphic cricket Gryllus rubens Scudder, we observed a greater gain in total and ovarian biomass in short-winged (SW) vs. long-winged (LW) crickets (Mole \& Zera 1993). This is consistent with the idea that there is a drain of organismal resources owing to the presence of flight muscles in the LW morph which reduces fecundity. Importantly, we documented that LW and SW morphs did not differ in food consumption or digestion when fed a nutritious diet ad libitum. This eliminated the possibility that the enhanced ovarian growth in the SW morph simply results from increased resource acquisition (Mole \& Zera 1993).

In our view, the existence of a trade-off such as that found in G. rubens is contingent upon two factors. First, there must be competing physiological traits or processes. Second, these processes must be dependent on a limited pool of resources within the organism. It is this second requirement that turns a potential trade-off into a realized one. If such internal resource limitation did not exist, then increased allocation to one process, such as egg production, might be accommodated by increased resource acquisition from the environment (increased consumption and digestion). This would obviate the trade-off by eliminating the required decrease in resources allocated to the alternate trait, with which it should otherwise trade off. The way in which the resources allocated to pairs of alternate traits is limited within organisms is poorly understood and this is the major point that we consider in this study. Here, we demonstrate that an organism which is physiologically capable of exhibiting a trade-off may not do so if its capacity to assimilate nutrients exceeds demand.

\section{Materials and methods}

\section{INSECTS AND REARING CONDITIONS}

The present study focuses on the sand cricket G. firmus Scudder. This species occurs in the south-eastern USA where it exists as a LW morph that is capable of flight or as a SW form that is flightless (Veazy et al. 1976). As in G. rubens, the SW morph of G. firmus is reported to be substantially more fecund than the LW morph (Roff 1984). The G. firmus used in the present study were derived from a colony founded from 20 SW females collected in Gainesville, Florida in the autumn of 1991 . The cricket colony had been maintained in a polymorphic state in the laboratory for about two generations prior to the experiments described here. All crickets were reared approximately 40 60 per 10 gallon aquarium at $28^{\circ} \mathrm{C}$ under a $16: 8 \mathrm{~h}$ light: dark photoregime. Individuals were fed a standard dry diet (Zera \& Rankin 1989) until they began the feeding trial (first day of the final stadium or as adults) after which time they were fed a standard wet diet (agar-based diet containing the same component as the 'dry diet'). Crickets were checked for molting at $24 \mathrm{~h}$ intervals.

\section{FEEDING EXPERIMENTS}

Feeding trials were conducted to estimate nutritional indices for LW and SW female G. firmus. Our main focus was on adults but nutritional indices were also determined for the final nymphal stadium in approximately half of the crickets studied. We acquired data for a total of 53 adult crickets (28 LW, $25 \mathrm{SW})$ and 30 final instars (10 LW, $20 \mathrm{SW}$ ). In adults, nutritional indices were measured from adult eclosion until the 14th day of adult life. This was done to be consistent with our earlier study and because it was during this period that morphs were thought likely to differ dramatically in egg production, based on the results of Roff (1984).

Newly molted crickets were withdrawn from the group-reared stocks at the beginning of the feeding trials and placed individually in $500 \mathrm{ml}$ containers. They were housed and fed in these containers for the remainder of the experiment. Crickets were mated to ensure normal egg development in adults. A pilot study on 21 females showed $88 \%$ mating success (spermatophore transfer) when each female was paired with one male for $2 \mathrm{~h}$ on 2 successive days. In the experiments we used more stringent conditions by placing females with males for $2-4 \mathrm{~h}$ on each of 5 con- 
Table 1. Equations defining terms used to analyze the consumption and utilization of food, adapted from Waldbauer (1968)

1. Growth $(\mathrm{GR})=$ weight gain of cricket (during the experiment)

2. Consumption $(\mathrm{CR})=$ feed ingested (during the experiment)

3. Efficiency of conversion of ingested food to body matter (ECI) is calculated as:

$\mathrm{ECI}=($ weight gain/feed ingested $) \times 100 \%$

where all weights are made on a dry weight basis GR can be expressed in terms of $\mathrm{CR}$ and $\mathrm{ECI}$, i.e. $\mathrm{GR}=\mathrm{CR} \times \mathrm{ECI}$.

4. Approximate digestibility (AD) is calculated as:

$$
\mathrm{AD}=\frac{\text { weight } \text { of feed ingested }- \text { weight of faeces }}{\text { weight of feed ingested }} \times 100 \%
$$

5. Efficiency of conversion of digested food to body matter $(\mathrm{ECD})$ is calculated as:

$$
\mathrm{ECD}=\frac{\text { weight gain }}{\text { weight of feed ingested }- \text { weight of faeces }} \times 100 \%
$$

Where all weights are made on a dry weight basis ECI can be expressed in terms of $A D$ and $E C D$, i.e. $\mathrm{ECI}=\mathrm{AD} \times \mathrm{ECD}$ and thus $\mathrm{GR}=\mathrm{CR} \times \mathrm{AD} \times \mathrm{ECD}$.

secutive days, beginning 5 days after adult molt. Mating was performed in separate containers without food so as to prevent consumption of the female's food supply by the males. After mating the males were returned to a large colony from which they were withdrawn for subsequent matings as needed. This procedure was designed to ensure that females were mated with several different males in an effort to prevent variation in individual male reproduction from affecting female performance. Beginning on the sixth day as adults, females were also allowed to oviposit into moist sand for $24 \mathrm{~h}$ every other day. Oviposited eggs were later collected by flotation in brine and counted.

Except for the time taken to mate and oviposit, the crickets were maintained in their individual $500 \mathrm{ml}$ containers in an incubator at $28^{\circ} \mathrm{C}$ with a $16: 8 \mathrm{~h}$ 1ight:dark photoregime. Nutritional indices (Waldbauer 1968 and Table 1) were calculated for each cricket using the same techniques as described in Mole \& Zera (1993). Briefly, this involved weighing each cricket at the beginning of the experiment, at adult molt and at the end of the experiment (day 14 of adulthood). Pre-weighed fresh food was provided every other day, at which time the remaining food and frass were removed for freeze drying and weighing. The same batch of food was used for all crickets in the experiment and the same procedures and precautions described in Mole \& Zera (1993) were taken to ensure the accurate estimation of the dry mass of food consumed by the crickets. Food consumption (CR) and all other nutritional indices (see Table 1) were calculated twice, once for the period of the final nymphal instar and then again for the first 2 weeks of adult life. The duration of the final instar was also recorded. As with our earlier report, estimates of ECD values (see Table 1) and growth (GR) on a dry weight basis depend on estimated initial dry body weights. Again, we used a separate but identically fed group of crickets drawn from the same stocks to generate a conversion factor for the ratio of live to dry weight, using crickets whose live-weight range spanned that of the crickets in the feeding trial.

At the conclusion of the feeding trials, the 14-day-old crickets were weighed and their flight (thoracic) muscles and ovaries were dissected and weighed. The dissections were carried out as described below. Both the flight muscles and the ovaries were stored frozen at $-20^{\circ} \mathrm{C}$ and subsequently analyzed for their Kjeldahl nitrogen contents.

\section{DEVELOPMENTAL PROFILES}

Developmental profiles for whole body, flight (thoracic) muscle and ovarian tissue weights were constructed using adult female crickets of each morph that were 1, 3, $5,7,9$ and 12 days old (day of adult eclosion $=$ day 0 ). The crickets used in this experiment were adults, individually housed and maintained in the same way as those in the parallel feeding experiment described above. Gravimetric analyses were supplemented with qualitative observations on flight muscle characteristics and Kjeldahl nitrogen determinations made on the flight muscle tissues. Initial body weights were recorded and the crickets were reweighed before dissection to determine weight gains. Before dissection the wings were also removed and weighed. Both ovaries were removed and weighed. Flight muscles were dissected out and their weights quantified as described in Mole \& Zera (1993). This involved dissecting dorso-longitudinal and dorso-ventral flight muscles free from fat bodies and other attached tissues. Flight muscles contained a small amount of attached cuticle $(<6 \%$ of the total wet weight) which was not removed because of its small mass and because of the difficulty in removing all the muscle from the cuticle.

For estimates of total nitrogen in flight muscles, the muscles were first dissolved free of the cuticle in $1 \mathrm{ml}$ of $10 \%$ aqueous $\mathrm{KOH}$. The solution of muscle tissue in $\mathrm{KOH}$ was then added to the Kjeldahl digest, preliminary experiments having shown that this did not adversely affect the digestion reaction. The digest also contained $4 \mathrm{ml}$ conc. $\mathrm{H}_{2} \mathrm{SO}_{4}, 1$ Kelmate catalyst tablet of $\mathrm{CuSeO}_{3}+\mathrm{K}_{2} \mathrm{SO}_{4}$ (Fisher Scientific, Fair Lawn, NJ, USA). In order to obtain sufficient sample for Kjeldahl analysis, flight muscles from more than one cricket were pooled together (3-4 SW and 1-2 LW individuals respectively). 


\section{STATISTICAL ANALYSES}

Statistical analyses were performed using a DOS SYSTAT 5.0 (Wilkinson 1990). Means provided in the text and tables are followed by standard errors. Sample sizes for the feeding trial are given in the experimental methods (above) and apply to all the analyses. In the case of Kjeldahl analyses on pooled samples of wings. sample sizes are given in the text following standard errors. Single-factor ANOVA and ANCOVA reported in the text all employ morph (SW or LW) as the main effect. As with our earlier report (Mole \& Zera 1993). we have followed Raubenheimer \& Simpson (1992) and used ANCOVA to replace traditional ANOVA-based analyses of nutritional indices. Data were approximately normally distributed as gauged by normal probability plots (Wilkinson 1990). Results from the dissection experiments were analyzed by two-factor ANCOVA, with age and morph as main effects and body weight as covariate, was determined to the day in the experiments and is treated as a categorical variable in our analyses. Significance levels and $F$-values associated with the main effects are reported in the text.

\section{Results}

\section{FEEDING TRIALS}

The nutritional indices determined from the feeding trials are presented in Table 2. We consider results for adults first. The live weights of SW and LW adults were statistically indistinguishable at both the beginning and the end of the experiment. The initial and final live weights were $480 \pm 20.9 \mathrm{mg}$ and $704 \pm 26.1 \mathrm{mg}$ respectively, for the SW morph. For the LW morph these were $516 \pm 14.8 \mathrm{mg}$ and $748 \pm 19.3 \mathrm{mg}$ respectively. Estimated dry weight gains (GR) are given in Table 2. There is no apparent distinction to be made between the morphs with respect to weight gain (GR) during this period of adult growth.

Interestingly, the results for $\mathrm{CR}$ and $\mathrm{AD}$ ('Table 2) show that LW individuals consumed significantly more food than SW individuals $\left(F_{1,50}=13.7, P<0.001\right)$ and that they also digested it somewhat more efficiently $\left(F_{1,50}\right.$ $=4.73, P<0.035)$. For $G$. firmus, it is apparent that the LW morph assimilated more nutrients than the SW morph by the combined action of a larger intake and a more efficient digestion. Because of these results for differing nutrient assimilation (CR and $\mathrm{AD}$ ) but similar growth (GR), we expected differences between the morphs in the efficiency with which assimilated nutrients were converted to new biomass (ECD). As expected, ECD is significantly greater for the SW vs the LW morph (Table 2). Table 2 also shows results for final instars. During this stage there are no differences between morphs for CR, AD or ECD. Differences between the morphs for biomass gain (GR) and instar duration are statistically significant. However, we are reluctant
Table 2. Growth analysis of female Gryllus firmus on a dry basis

\begin{tabular}{lccl}
\hline & SW & \\
\cline { 2 - 3 } & \multicolumn{2}{c}{ MW } & \\
Measurement* & \multicolumn{2}{c}{$P$} \\
\hline Adults & & & \\
GR (mg) & $62 \pm 5$ & $64 \pm 4$ & NS \\
CR (mg) & $730 \pm 54$ & $981 \pm 42$ & 0.001 \\
AD (\%) & $59 \pm 3 \cdot 6$ & $67 \pm 2 \cdot 2$ & 0.035 \\
ECD $(\%)$ & $8.7 \pm 0.8$ & $5.2 \pm 0.9$ & 0.02
\end{tabular}

\section{Final instar}

\begin{tabular}{lccl} 
GR (mg) & $49 \pm 4$ & $64 \pm 5$ & $0 \cdot 05$ \\
CR (mg) & $869 \pm 79$ & $1036 \pm 125$ & NS \\
AD (\%) & $82 \pm 2 \cdot 9$ & $75 \pm 3 \cdot 4$ & NS \\
ECD (\%) & $9 \cdot 1 \pm 1 \cdot 3$ & $8 \cdot 8 \pm 1 \cdot 0$ & NS \\
Instar (days) & $11 \cdot 4 \pm 0 \cdot 15$ & $12 \cdot 1 \pm 0 \cdot 37$ & $0 \cdot 05$ \\
\hline
\end{tabular}

* See Table 1 for explanation of terms and formulae used in calculations.

$\uparrow$ Probabilities for between-morph differences were obtained from ANOva for GR, initial mass and CR and ANCOVA for index data. See Materials and methods for sample sizes and details of statistical analyses.

to attribute any biological significance to these differences as they were only of marginal significance $(P=0.05$, both cases), so that one of these differences is likely owing to chance.

The weight of the flight muscles in the adult female crickets dissected at the end of the feeding trial was significantly $\left(\mathrm{F}_{1,50}=38.2, P<0.001\right)$ greater in $\mathrm{LW}(57 \pm 2.94$ $\mathrm{mg})$ vs SW crickets $(36 \pm 1.67 \mathrm{mg})$. Ovary weights of SW crickets $(146 \pm 14.0 \mathrm{mg})$ were indistinguishable from those of LW individuals $(126 \pm 12.3 \mathrm{mg})$. but in each morph the weights of the ovaries were substantially larger than the flight muscles. As with ovarian weights, we were also unable to see any differences between morphs in the numbers of eggs oviposited (LW $85 \pm 15$; SW $82 \pm 16$ ).

\section{DEVELOPMENTAL PROFILES}

Figure 1 shows the increase of (live) body weight over time. Note that each point on the curve is for a different group of crickets weighed only once. at the time of dissection, rather than for a single cohort tracked through time. There is considerable variation in the data and we used an ANCOVA with initial weight as covariate, to examine the effects of age and morph on body weight. As expected. most of the variation is the result of the increasing trend in body weight with age $\left(F_{5,87}=12,122, P<0.001\right)$, and as with the feeding trials, there is no significant effect of morph on body weight. 
Figure 2 shows the increase of ovarian mass with age. Again, there is considerable variation in the data but it is evident that ovary weight increases with age in both morphs. An ANCOVA of ovary weight. with body weight as covariate showed that age $\left(F_{5,87}=16.6, P<0.000\right)$, was the only significant main effect in the analysis. This result is also consistent with the absence of a difference in ovarian mass between morphs at the end of the feeding trials (see above). One difference between the morphs (see Fig. 2 ) is that ovarian mass increased faster in the SW morph relative to the LW morph during the first week of adulthood while LW ovaries caught up on days 7 to 12 .

This is reflected in a significant morph $\times$ age interaction $\left(F_{5,87}=3.74, P<0.004\right)$ which allows for the possibility that the SW morph may be able to lay eggs a few days earlier than the LW morph. At present we are investigating the possibility that the SW morph exhibits increased reproduction early in adulthood but not overall.

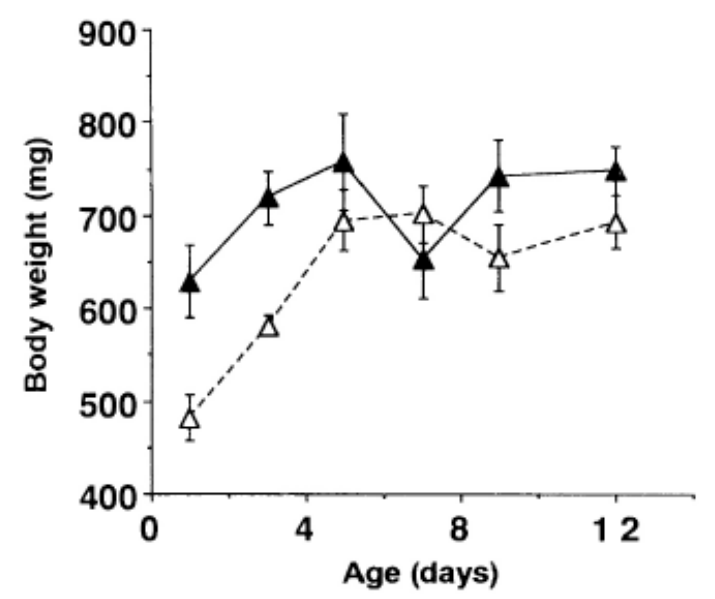

Fig. 1. Cricket body weight (live mass, mg) vs age (days after adult molt). Each point on the graph is a mean for a different group of crickets. The graph does not indicate changes in the same individuals over time. Error bars indicate standard errors. (-) LW morph; (--) SW morph.

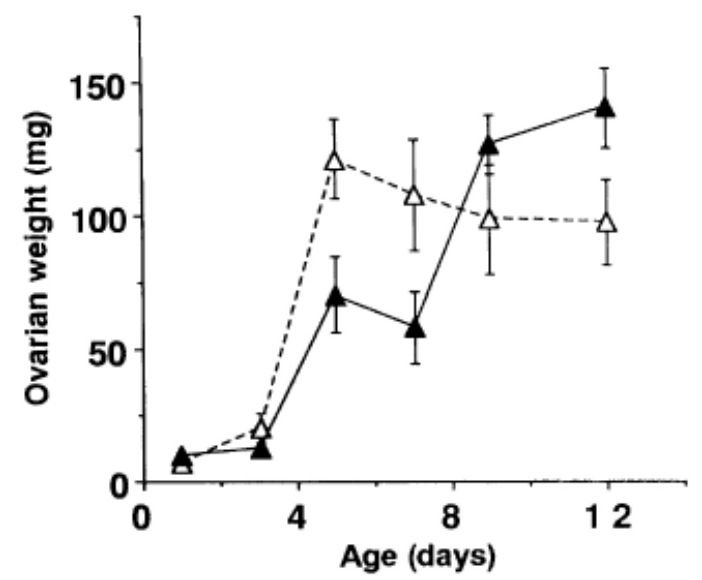

Fig. 2. Ovarian weight (live mass, mg) $v s$ age (days after adult molt). Error bars indicate standard errors. (-) LW morph; (---) SW morph.

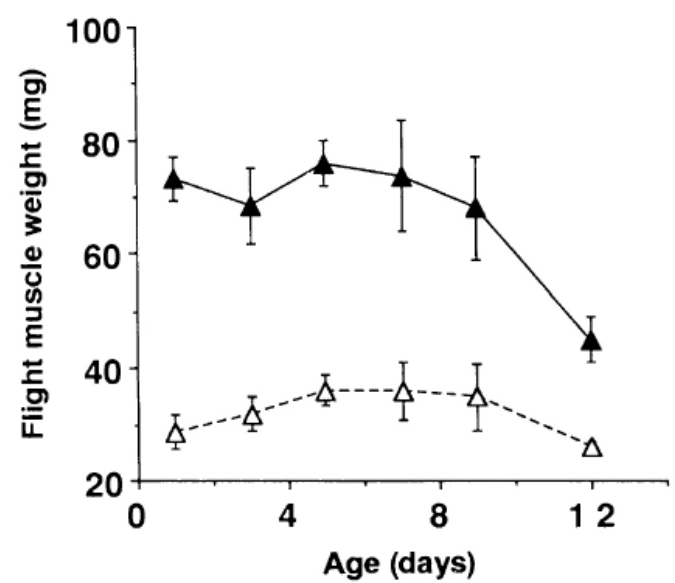

Fig. 3. Thoracic (flight) muscle mass (live mass, mg) vs age (days after adult molt). Error bars indicate standard errors. (-) LW morph; (---) SW morph.

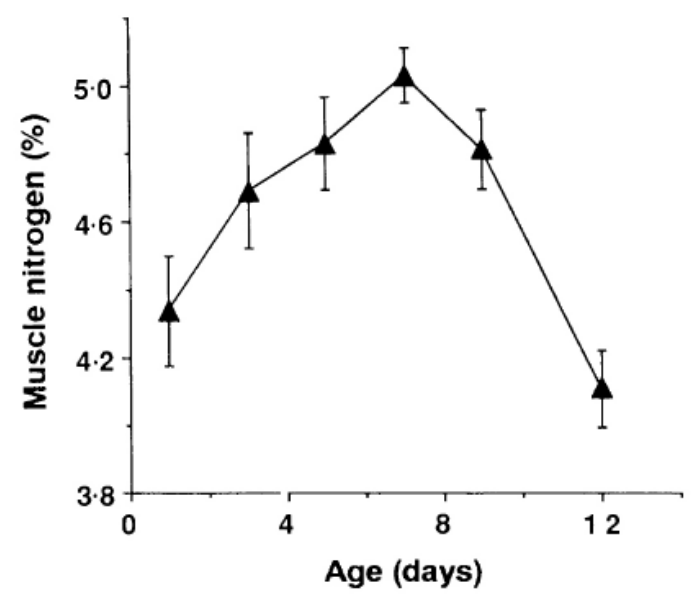

Fig. 4. LW thoracic (flight) muscle nitrogen content $(5 \% \mathrm{~N}, \mathrm{w} / \mathrm{w}) \mathrm{vs}$ age (days after adult molt). Error bars indicate standard errors.

Figure 3 presents the developmental profile of flight muscle mass. LW muscles are clearly heavier than those of the SW morph throughout the first 12 days of adulthood $\left(F_{5,87}=95.2, P<0.000\right.$, ANCOVA, body weight as covariate). Unlike the ovaries. the flight muscle masses are relatively invariant with age although they do show a significant but slight decline with age $\left(F_{5,87}=8.87, P<0.000\right)$. They also differ from ovaries in that they exhibit no significant growth after adult molt.

No difference in the nitrogen content per unit (live) mass of muscle could be detected between LW and SW morphs (LW $4.68 * 0.12 \%$. SW 4.75 f $0.17 \%$ ). The profile for nitrogen concentration vs age for LW crickets (Fig. 4) shows a peak in nitrogen levels at day 7 and then a clear decline. An ANOva revealed that this age effect is significant $\left(F_{5,26}=5.27, P<0.00\right)$ as is the convex shape of the curve (second-order polynomial: $F_{1,26}=24.1, P<0.000$ ).

Nitrogen contents of flight muscle tissues from crickets used in the feeding trial were similar to those of crickets used to construct the developmental profiles (intermediate between days 9 and 12, see Fig. 4). The nitrogen concen- 
tration per unit tissue mass was higher in the ovaries (LW $5.12 \pm 0.1496$, SW $5.26 \pm 0.19 \%$ ) than in the flight muscles (LW $4.30 \pm 0.10 \%$, SW $4.70 \pm 0.10 \%$ ) but there were no significant differences between morphs for either tissue. The weight of the wings (both hind- and forewings) was found to be quite small relative to flight muscle mass. For the LW morph the two pairs of wings weigh $6.02 \pm 0.37 \mathrm{mg}$ $(n=42)$ and for the SW morph they weigh $2.59 \pm 0.20 \mathrm{mg}$ $(n=103)$. The concentration of nitrogen in the wings does not differ between morphs and is similar to that in muscles (A. J. Zera, S. Mole \& K. Rokke, in press). Thus, the mass of nitrogen in wings is negligible relative to that in ovaries or flight muscles.

\section{Discussion}

Collectively, our present results indicate that the female reproductive and flight apparatus of G. firmus have all the characteristics that would lead one to expect a tradeoff between flight capacity and fecundity. Indeed, there are striking parallels between the situation in this species and that previously reported for G. rubens where a trade-off has been documented (Mole \& Zera 1993). Nevertheless, a trade-off between flight capability and fecundity does not occur in G. firmus over the first 14 days of adulthood. In this species LW individuals are apparently able to compensate for the energetic demands of flight capability by consuming more food. In what follows we first make the argument that the potential for a flight capability $v s$ fecundity trade-off is indeed present in G. firmus. Then we consider the aspects in which G. firmus differ from G. rubens and which lead to the obviation of this potential trade-off.

The present results for G. firmus show that the flight muscles of the LW morph are substantially larger than those of the SW morph throughout the first 2 weeks of adulthood. It is also evident that the flight muscles are essentially at full size at adult molt and that there is no net growth in flight muscle mass in either morph during this period. In contrast, the ovaries of G. firmus are quite small at adult molt, but they grow substantially during the first 2 weeks of adult life. These data parallel our earlier study of G. rubens. Thus, for both G. rubens and G. firmus. there is a temporal separation of flight muscle construction and ovarian growth. This temporal separation has important consequences for the dynamics of any trade-off in that it precludes a direct physiological trade-off between the processes involved in the construction of the flight apparatus and reproductive tissues.

While we can discard the hypothesis of a direct tradeoff between flight muscle and ovarian growth (i.e. tissue construction), these anatomical data are consistent with a trade-off involving flight muscle maintenance costs in both species. We believe that the maintenance and respiratory costs of functional flight muscles drain reserves that would otherwise go to ovarian growth. The rationale for this is that the respiration of metabolites by muscle tissues, or tissues involved in flight fuel synthesis. could lead to their loss as $\mathrm{CO}_{2}$ while the same metabolites would likely be retained as egg mass if allocated to ovarian growth. This differential biomass loss would then lead to the observed differences in ECD between the morphs. This argument follows because almost all of the ovarian mass is egg mass, which is effectively storage tissue. In contrast, muscle tissue is likely to have a significant basal metabolism even when at rest (Slama 1984).

The lower ECD that we have found for LW G. firmus relative to the SW morph (Table 2) is consistent with this hypothesis. This reduced ECD in the LW morph is the second important parallel with G. rubens (Mole \& Zera 1993) and adds to the expectation of a tradeoff in G. firmus via the same mechanism. We now turn to two important differences between the species and to the critical question of whether increased allocation to flight capability in LW $G$. firmus leads to a reciprocal drain of resources from reproduction. In contrast to our previous results which show that LW $G$. rubens exhibits reduced overall growth, ovarian growth and egg production, we have no evidence for reduced biomass gain. ovarian growth or oviposition in LW G. firmus in our feeding trials. This difference in performance between the species does not suggest that the reproductive output of LW G. firmus is accomplished at the expense of other organismal traits. Instead, we propose that interspecific differences in food consumption cause these differences.

In LW G. firmus, the additional resources allocated to the maintenance of the flight apparatus appear to be provided by the significant increase in food consumption over that in the SW morph (Table 2). rather than a diversion of resources away from the reproductive system. This change in resource acquisition obviated the trade-off that we had expected from our study of $G$. rubens. Importantly. in both of these studies, identical conditions were used in feeding and housing the crickets. In particular, both species were maintained at the same temperature, under the same photoperiod and in identical containers. Moreover. in both studies they were fed the same highly nutritious diet, presented ad libitum. without feeding competition from other individuals. Because of this, we feel that the differences between G. rubens and G. firmus are the result of biological differences between species rather than differences in experimental conditions. In the preceding discussion we have argued that there is no evidence for a net flight capability $v s$ fecundity trade-off between the morphs over the entire feeding trial. However, this does not preclude the existence of trade-offs between morphs that are of shorter duration, or of trade-offs between organs within individuals over the period of the feeding trials. Indeed, our dissection experiment indicates that such trade-offs may have occurred, but that their effects cancelled each other out when averaged over the duration of the feeding trial. 
By the end of the first week of adulthood, the SW morph has a greater ovarian mass than the LW morph (Fig. 2 ). This is consistent with a trade-off of flight capability $v s$ fecundity between the morphs, similar to that reported previously for G. rubens (Mole \& Zera 1993). However, this evidence is not definitive because we do not have the nutritional index data for this specific time period that are necessary to document a trade-off at the resource level (Mole \& Zera 1993). During the second week of adulthood, increased ovarian growth in the LW morph caused the LW ovaries to attain the same mass as SW ovaries. This enhanced ovarian growth in the LW morph may have been, at least in part, the result of a mobilization of nitrogen from the flight muscles as well as a diversion of resources away from flight muscle maintenance. Flight muscles in the LW morph begin decreasing in nitrogen content and mass at approximately the same day (day 7) that ovarian mass begins a dramatic increase in size. Again, our evidence is consistent with a trade-off, but we do not have the physiological data to document definitively a reallocation of resources between flight capability and ovarian growth in the LW morph. Such an intramorph tradeoff is much less likely for the SW morph which emerges as an adult with reduced flight muscles. If these inter- and intramorph trade-offs occurred, they must have cancelled each other out as there is no net trade-off between the morphs over the entire feeding trial.

To summarize, the general pattern of development for flight muscles and ovaries appears to be similar in both $G$. rubens and G. firmus, especially when considered at the beginning and the end of 2-week feeding trials. This similarity between species also holds for ECD and the likely physiological costs associated with the maintenance of flight apparatus or other costs associated with flight capability (e.g. triglyceride synthesis). However, in conditions where food is freely available, these two species differ in their consumption and assimilation of resources. With $G$. firmus, it appears that food assimilation by the LW morph is higher relative to the SW morph so that the resource drain resulting from the functional flight apparatus is obviated, i.e. there is no negative impact on ovarian growth over the period of the experiment. This was not the case for G. rubens over the same experimental period. In this species the drain on resources resulting from a functional flight apparatus occurs at the expense of resources allocated to reproduction in the LW morph (Mole \& Zera 1993).

These results raise interesting questions concerning physiological and ecological aspects of life histories. At the physiological level, it appears that organismal traits unrelated to the trade-off (e.g. consumption and digestion) may influence whether a trade-off of resources can occur between two organismal characteristics (e.g. between flight and fecundity). Specifically, additional consumption by the LW morph of G. firmus appears to elevate reproduc- tion to that of the SW morph. This raises the question of why SW individuals did not eat more, and suggests that morphological constraints such as abdomen size might prevent the SW morph from consuming additional food. This scenario raises the possibility that the internal pool of resources available for allocation to flight capability and fecundity may be determined by the physiological capacity of the gut or the other physiological or behavioral processes involved in the consumption, digestion and absorption of food. A parallel situation to the failure of SW G. firmus to consume additional food was reported by Tanaka (1993), who found that one morph of Modicogryllus confirmatus produced fewer eggs and consumed less food than the alternate morph when fed ad libitum. These results underline the need for further studies to understand resource acquisition as well as allocation, and they serve as a reminder that we have a poor understanding of how an organism functions as a set of interacting traits (Feder et al. 1987).

Irrespective of the capacity of an organism to acquire resources, a trade-off that is based on levels of internal resources may occur when their supply in the environment is the limiting factor, rather than the physiological ability of the organism to acquire them. The ecological implications of this are interesting. In resource-poor environments tradeoffs may occur, or be accentuated, because they cannot be obviated by additional consumption. Physiological mechanisms allocating resources among traits will be critical in understanding the trade-off in such conditions. In luxury environments, where trade-offs are realized, they will be present because of physiological or behavioral constraints that limit resource acquisition. Where a potential trade-off is not realized in luxury conditions, such constraints will be absent and the traits may use resources at rates determined by their own capacities to do so.

One positive result from this analysis is that it allows us to pinpoint key processes that determine the existence and realization of trade-offs. These data also allow for a possible explanation of conflicting results from different laboratories. For example, we observed no significant difference in fecundity and only minor differences in ovarian growth between wing morphs of G. firmus during the first 2 weeks of adulthood. This contrasts with the substantially higher fecundity of SW vs LW females maintained over the first 3 weeks of adult life in one study (Roff 1984) but not in another (Roff 1990). This sporadic observation of morph-specific differences in fecundity is likely owing to a variety of factors which differed between the studies (temperature, photoperiod, food type, rearing density). We have subsequently (unpublished results) compared fecundity between wing morphs of G. firmus under a variety of environmental conditions and have found significantly greater fecundity of the SW morph in some cases but no difference between morphs in others. It therefore appears that the elevated fecundity of the SW morph in G. firmus is 
contingent upon environmental conditions as has been reported for other flight polymorphic insects (Young 1965). This serves to emphasize that trade-offs are not entirely organism level phenomena and can only be fully understood when environmental conditions that affect the trade-off are identified.

\section{Acknowledgements}

We thank K. Grudzinski and M. McGreer for technical assistance. This work was supported by NSF grant BSR9107429 to A.J.Z. and S.M.

\section{References}

Begon, M., Harper, J. L. \& Townsend, C. R. (1986) Ecology: Individuals, Populations and Communities. Blackwell Scientific Publications, Oxford.

Calow, P. (1979) The cost of reproduction: a physiological approach. Biological Reviews, 54, 23-40.

Feder, M. E., Bennet, A. F., Burggren, W. W. \& Huey, R. B. (1987) New Directions in Ecological Physiology. Cambridge University Press, Cambridge.

Fisher, R. A. (1930) The Genetical Theory of Natural Selection. Clarendon Press, Oxford.

Harrison, R. G. (1980) Dispersal polymorphisms in insects. Annual Reviews of Ecology Systematics, 11, 95-118.

Haukioja, E. \& Hakala, T. (1986) Life-history evolution in Anodonta piscinalis: correction of parameters. Oecologia, 35, 253-266.

Johnson, C. G. (1969) Migration and Dispersal of Insects by Flight. Methuen, London.

Mole, S. \& Zera, A. J. (1993) Differential allocation of resources underlies the dispersal-reproduction trade-off in the wing-dimorphic cricket, Gryllus rubens. Oecologia, 93, 121-127.

Nylin, S., Wiklund, C., Wickman, P. \& Garcia-Barros, E. (1993) Absence of trade-offs between sexual size dimorphism and early male emergence in a butterfly. Ecology, 74, 1414-1427.

Pener, M. (1985) Hormonal effects on flight and migration. Comprehensive Insect Physiology, Biochemistry and Pharmacology, vol. 8 (eds. G. A. Kerkut \& L. I. Gilbert), pp. 491-550. Pergamon Press, New York.

Pianka, E. R. (1981) Resource allocation among animals. Physiological Ecology: An Evolutionary Approach to Resource Use (eds. C. R. Townsend \& P. Calow), pp. 491-550. Blackwell Scientific Publications, Oxford.

Raubenheimer, D. \& Simpson, S. J. (1992) Analysis of covariance: an alternative to nutritional indices. Entomolgia Experimentalis et Applicata, 62, 221-231.

Reekie, E. G. \& Bazzaz, F. A. (1987) Reproductive effort in plants, 1. Carbon allocation to reproduction. American Naturalist, 129, 887-896.
Reznick, D. (1983) Costs of reproduction: an evaluation of the empirical evidence. Oikos, 44, 257-267.

Roff, D. A. (1984) The cost of being able to fly: a study of wing polymorphism in two species of crickets. Oecologia, 63, 30-37.

Roff, D. A. (1986) The evolution of wing dimorphism in insects. Evolution, 40, 1009-1020.

Roff, D. A. (I 990) Antagonistic pleiotropy and the evolution of wing dimorphism in the sand cricket, Gryllus firmus. Heredity, 65, 169-177.

Roff, D. A. (1992) The Evolution of Life Histories. Chapman \& Hall, New York.

Slama, K. (1984) Microrespirometry in small tissues and organs. Measurement of Ion Transport and Metabolic Rate in Insects (eds. T. J. Bradley \& T. A. Miller), pp. 100-120. Springer-Verlag, New York.

Slansky, F. \& Feeny, P. P. (1977) Maximization of the rate of nitrogen accumulation by larvae of the cabbage butterfly on wild and cultivated food plants. Ecological Monographs, 47, 209-228.

Stearns, S. C. (1989) Trade-offs in life-history evolution. Functional Ecology, 3, 259-268.

Stearns, S. C. (1992) The Evolution of Life Histories. Oxford University Press, Oxford.

Tanaka, S. (1993) Allocation of resources to egg production and flight muscle development in a wing dimorphic cricket, Modicogryllus confirmatus. Journal of Insect Physiology, 39, 493498.

Tuomi, J., Haukioja, E. \& Hakala, T. (1983) Alternative concepts of reproductive efforts, costs of reproduction and selection of lifehistory evolution. American Zoologist, 23, 25-34.

Veazy, J. N., Kay, C. A. R., Walker, T. J. \& Whitcomb, W. H. (1976) Seasonal abundance, sex ratio and macroptery of field crickets in Northern Florida. Annals of the Entomology Society of America, 69, 374-380.

Waldbauer, G. P. (1968) The consumption and utilization of food by insects. Advances in Insect Physiology, 5, 229-288.

Wilkinson, L. (1990) SYSTAT: The System for Statistics. Systat Inc., Evanston, IL.

Williams, G. C. (1966) Natural selection, the costs of reproduction and a refinement of Lack's principle. American Naturalist, 100, 687-690.

Young, E. C. (1965) Flight muscle polymorphism in British corixidae: ecological observations. Journal of Animal Ecology, 34, 353-389.

Zera, A. J. \& Rankin, M. A. (1989) Wing dimorphism in Gryllus rubens: genetic basis of morph determination and fertility differences between morphs. Oecologia, 80, 249-255.

Zera, A. J., Mole, S. \& Roke, K. (1995) Lipid, carbohydrate and nitrogen content of long-winged and short-winged G. firmus: implications for the physiological cost of flight capability. Journal of Physiology, in press.

Submitted November 1993; revised April 1994; accepted April 12, 1994 